\title{
INDUSTRIA LÍTICA TALLADA DEL AJUAR FUNERARIO DEL ABRIGO I DE CUEVA MATURRAS (ARGAMASILLA DE ALBA, CIUDAD REAL). ANÁLISIS TECNOLÓGICO Y FUNCIONAL
}

\author{
Lithic industry of the grave good from Maturras Cave I \\ (Argamasilla de Alba, Ciudad Real). Technological and \\ functional analysis
}

\section{Carmen Gutiérrez Sáez, Ignacio Martín Lerma, Juan A. Marín de Espinosa Sánchez y Belén Márquez Mora*}

Recibido el 19 de febrero de 2008. Aceptado el 13 de marzo de 2008.

Resumen. Durante la excavación del conjunto funerario de Cueva Maturras se recuperaron 18 puntas de flecha y tres láminas, todo en sílex. El nivel puede adscribirse a un momento impreciso entre el Neolítico final y el Calcolítico pleno. Este lote, que constituye la única industria lítica tallada de todo el ajuar, se ha analizado tanto desde el punto de vista tecnológico como funcional en un intento de acercarnos más a la comprensión de los grupos humanos de la Prehistoria reciente.

Palabras clave: Neolítico. Calcolítico. Mundo funerario. Tecnología. Funcionalidad. Industria lítica.

Abstract. Eighteen arrowpoints and three lams made of flint were recovered during the excavation of the funerary deposit of Cueva Maturras. This level can be dated into an imprecise moment between late Neolithic and Upper Calcolithic. This sample, which is the only knapped lithic industry of all the goods, has been studied from both technologic and functional point of view in order to a better understanding of recent prehistory human groups.

Key Words: Neolithic. Calcolithic. Funerary world. Technology. Use-wear analysis. Lithic industry

\section{INTRODUCCIÓN}

El abrigo 1 de cueva Maturras, en el municipio de Argamasilla de Alba (Ciudad Real), forma parte de un sistema de tres pequeñas cavidades comunicadas entre sí y situadas en la margen derecha del Guadiana Alto sobre el pantano de Peñarroya, dentro del conjunto de las Lagunas de Ruidera.
Las tres cavidades fueron sondeadas en el año 1996 pero únicamente en el abrigo 1 se localizó un nivel arqueológico que fue excavado en las campañas de 1998 y $2000^{5}$ Durante el trabajo arqueológico se exhumaron tres individuos con diverso ajuar funerario integrado por industria lítica pulimentada - un hacha y dos azuelas-, cerámica -tres vasijas prácticamente completas y algunos fragmentos- y

(*) Carmen Gutiérrez Sáez: Dpto. de Prehistoria y Arqueología, Universidad Autónoma. Madrid. carmen.gutierrez@uam.es Ignacio Martín LeRma: Dpto. de Prehistoria y Arqueología, Universidad Nacional de Educación Distancia. Madrid. imartin@bec.uned.es Juan A. Marín de Espinosa Sánchez: Museo del Cigarralejo. Murcia. info@tallarsilex.com

BelÉn MÁrouez Mora: Museo Arqueológico Regional de la Comunidad de Madrid. Alcalá de Henares, Madrid. belen.marrquez@madrid.org

(1) Las excavaciones estuvieron al cargo de un equipo integrado por A. Gómez Laguna, A. Ocaña Carretón y C. Gutiérrez Sáez. 

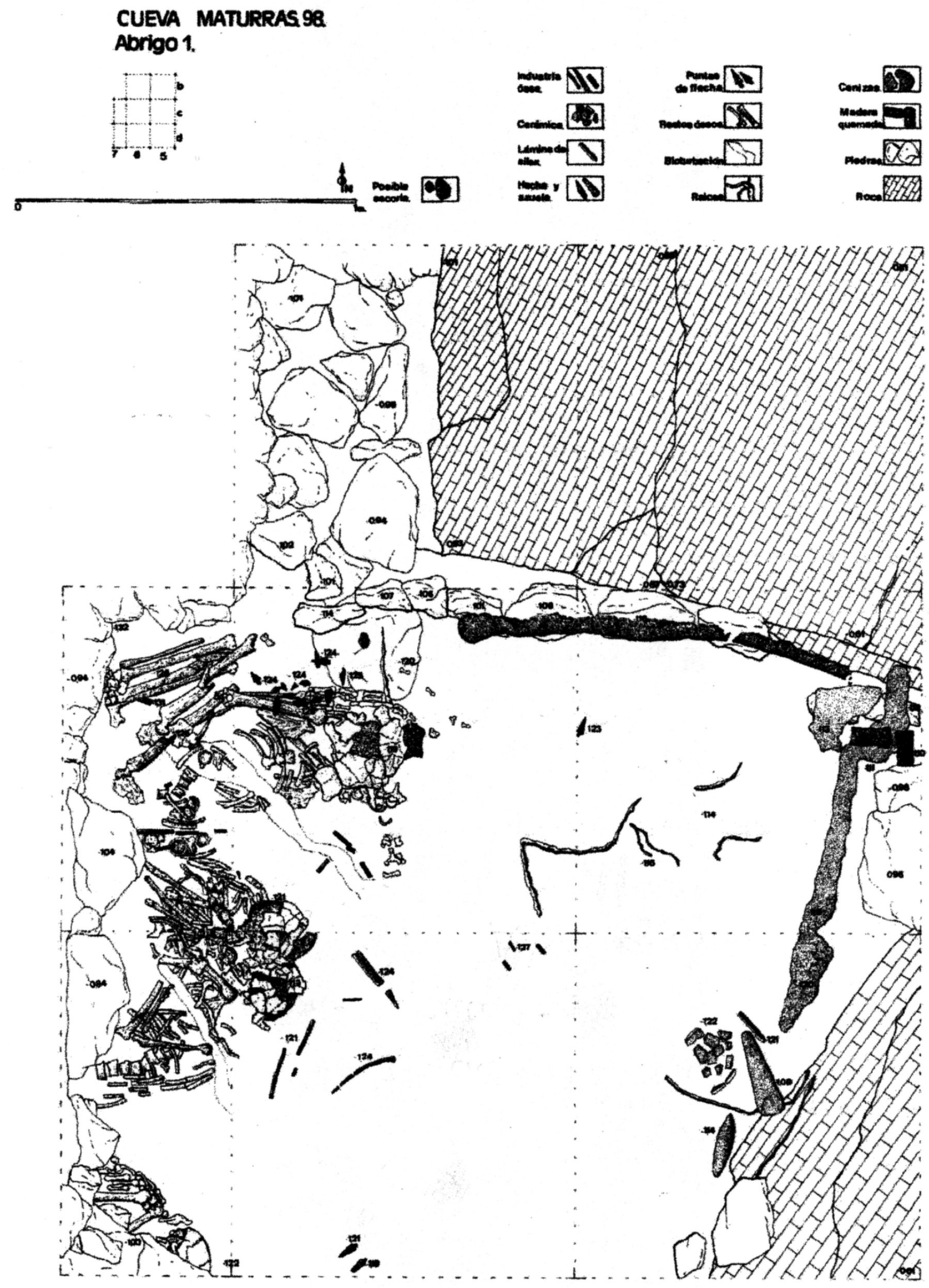

\ Figura 1. Plano del conjunto funerario de Cueva Maturras, campaña de 1998. Dibujo A. Gómez Laguna. 
ósea -varias espátulas, punzones y agujas en hueso-, así como por la industria lítica tallada objeto de este trabajo. El conjunto funerario presentaba evidencias de haber sido cuidadosamente clausurado; en primer lugar se aplicó fuego al recinto, una vez apagado fue cubierto todo por una capa de calcarenita blanca y finalmente sellado con bloques de piedra propios de la cavidad y otros traídos del exterior. Esta clausura ha posibilitado que el nivel funerario haya llegado intacto hasta su excavación, lo que constituye un fenómeno poco frecuente dentro del mundo funerario en cueva de la Prehistoria reciente. El nivel funerario puede haberse ocupado entre el Neolítico final y el Calcolítico pleno (Ocaña Carretón, Gómez Laguna, Gutiérrez Sáez y Sanguino González, 1999; Gutiérrez, Gómez y Ocaña, 2000; Gutiérrez Sáez, Gómez Laguna y Ocaña Carretón, 2002).

El conjunto del ajuar lítico tallado procedente del enterramiento colectivo está compuesto por 21 piezas, de las cuales 3 son hojas y 18 puntas de flecha. Este material presentaba una distribución peculiar. De las 18 puntas de flecha, 15 aparecieron asociadas al individuo 1, estando las otras tres dispersas sobre el suelo de la cavidad; por su parte, de las tres láminas, dos de ellas formaban parte del ajuar del mismo individuo. La tercera lámina se localizó junto a unos fragmentos cerámicos y dos grandes piezas pulimentadas - hacha y azuela- en un espacio aislado y separado de los cadáveres, constituyendo, quizá, un ajuar de carácter colectivo.

Las lecturas tecnológica y traceológica de los útiles en silex se han visto dificultadas como consecuencia de la fuerte acción térmica a la que ha sido sometido el material documentado, si bien las láminas ofrecen mejor aspecto al microscopio. A simple vista las piezas presentan un brillo que cubre toda la superficie, fuerte decoloración exterior y deshidratación interior; a menudo una red de fisuras recorre parte de las piezas llegando a provocar fracturas. Son frecuentes, así mismo, las cúpulas térmicas.

\section{LAS HOJAS}

El estudio y reconocimiento de las modalidades de desbastado laminar en la industria lítica documentada en poblados y contextos de enterramientos colectivos durante el calcolítico peninsular, así como la determinación técnica y morfológica de los atributos que caracterizan el material lítico tallado han partido del referente experimental en Europa a comienzos de la década de los 80 (Binder, 1984; Pelegrin 1984, 1988; Texier, 1984 a y b), y de posteriores trabajos que establecen modelos estadísticos (Gallet, 2002). La aplicación de estos referentes experimentales al material lítico arqueológico está permitiendo una comprensión más ajustada de procesos de talla específicos, como la presión, documentados en la Prehistoria Reciente (Forenbaher, 1999; Palomo i Pérez y Gibaja Bao, 2003; Terradas, Palomo, Gibaja y Clop, 2005).

De las tres hojas exhumadas en el Abrigo I de Cueva Ma- turras, sólo una de ellas se conserva entera, siendo los otros dos ejemplares un fragmento mesial y otro próximo-mesial. Se trata de tres grandes ejemplares de perfil recto, fino espesor en su parte mesial, aristas rectilíneas, largas y paralelas -que configuran una sección trapezoidal-, así como ausencia de ondulaciones en el reverso de las piezas. Los dos talones conservados son diedros y su anchura es menor que la máxima localizada en la parte intermedia de las hojas (Inizan, 1995: 79-80).

Tabla I. Medidas de longitud, anchura, espesor y peso

\begin{tabular}{|c|c|c|c|c|}
\hline Soporte & $\begin{array}{c}\text { Longitud } \\
(\mathbf{m m})\end{array}$ & $\begin{array}{c}\text { Anchura } \\
(\mathbf{m m})\end{array}$ & $\begin{array}{c}\text { Espesor } \\
(\mathbf{m m})\end{array}$ & $\begin{array}{c}\text { Peso } \\
(\mathbf{g r})\end{array}$ \\
\hline Hoja completa & 206 & 21,5 & 6,2 & 27,04 \\
\hline $\begin{array}{c}\text { Frag. } \\
\text { meso-proximal }\end{array}$ & 98,2 & 20 & 4,2 & 12,89 \\
\hline Frag. Mesial & 99 & 20 & 7 & 15,02 \\
\hline
\end{tabular}

La hoja completa, de gran longitud, acaba en una extremidad distal apuntada y simétrica delineando una rectitud marcada en sus perfiles. En el reverso del extremo distal observamos un levantamiento espontáneo (fig. 2-2) debido, probablemente, al sistema de inmovilización para la obtención de hojas por presión, efectuada con una muleta ventral o una palanca de vástagos en "T", sujetando el núcleo mediante un cajeado vertical y una presión ejercida desde el extremo distal. La rectitud de la hoja deduce la presión ejercida mediante una muleta o presionador rígido (Pelegrin, com. pers.). Como técnica para la obtención de este tipo de soporte laminar nos inclinamos por un sistema de presión con palanca, debido a la longitud de la gran hoja de silex que alcanza $206 \mathrm{~mm}$. Por las características indicadas la pieza puede proceder de una explotación unipolar del frente amplio del núcleo, no observándose negativos de extracciones bipolares.

En la hoja completa la punta ha sido configurada mediante un fino retoque en su extremo distal realizado por presión en ambos filos, no perceptible a simple vista (fig. 2-1). Por otra parte la terminación de los levantamientos tiende a extinguirse en el eje de simetría de la pieza, que parece coincidir con restos de córtex o de una pequeña geoda.

El fragmento próximo-mesial termina en una fractura oblicua y, en su cara dorsal, se observa una gran escama térmica. Finalmente en el fragmento mesial un retoque simple marginal recorre sus filos adoptando un carácter más abrupto hacia el extremo distal. En la conformación de talón die- 

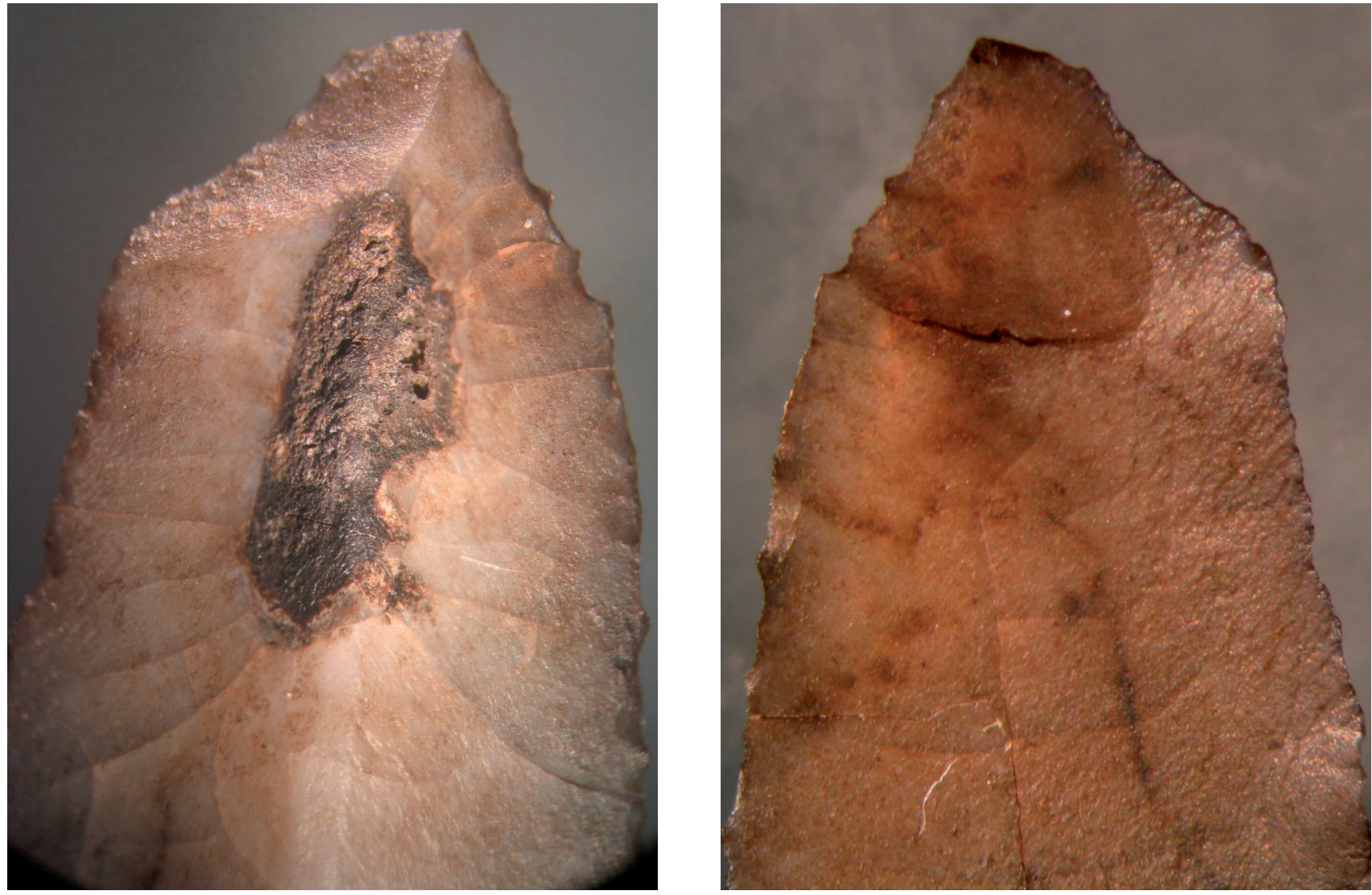

- Figura 2. Extremo distal de la lámina-cuchillo. Caras dorsal -1- y ventral -2-. 10x

dro de la hoja fragmento meso-proximal se ha partido de la percusión indirecta para, a continuación, acondicionar la arista mediante una extracción perpendicular al plano de percusión y alineada al eje de simetría, una percusión con un ángulo oscilante de unos $15^{\circ}$.

El análisis traceológico ha revelado un uso amplio de las piezas pero no intenso. La lámina completa ofrece a lo largo de ambos bordes laterales huellas de un trabajo longitudinal sobre una materia blanda o semiblanda y, en menor medida una dura que, con dudas, pudieran ser piel o carne y hueso. El pulimento aparece mal conservado ubicándose sobre ambas caras y filo de los dos bordes, presenta un aspecto poco compacto y apagado, con algún punto más espeso; en la zo-

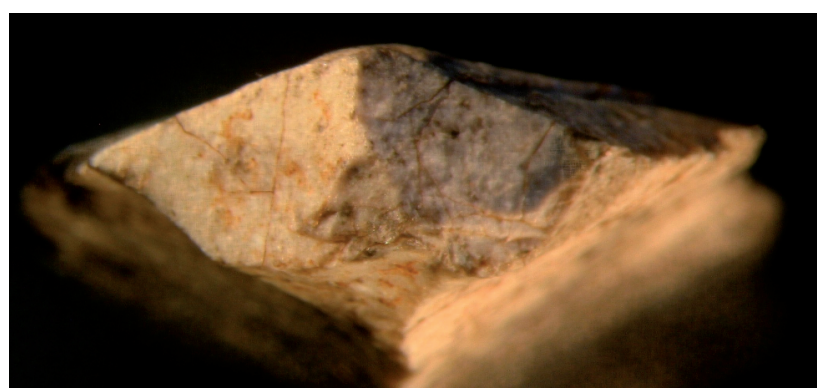

A Figura 3. Talón del fragmento meso-proximal de hoja. 10x na media se detecta también cierto embotamiento sobre los filos. Dado que en la pieza se observa un ligero lustre de fuego no parece posible apurar más la interpretación de la materia trabajada. Las estrías y rasgos lineales, en general, son muy claros sugiriendo una acción de tipo longitudinal como cortar. Por su parte los desconchados presentan una disposición linear y discontinua ocupando largas áreas del borde; son, además, algo menos numerosos sobre la cara ventral. En ambos bordes, los usos dados no han agotado la funcionalidad del instrumento. Esta pieza, que configuraría un posible cuchillo de carnicería, formaba parte de los enseres del difunto $n^{\circ} 1$ junto con las puntas de flecha, constituyendo un ajuar de tipo individual.

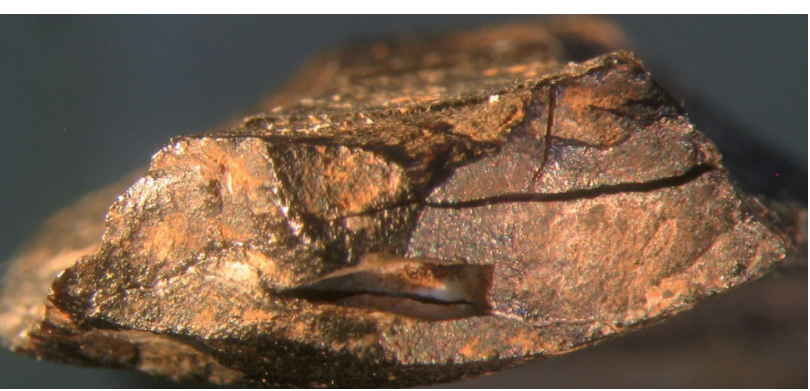

- Figura 4. Talón de la hoja-cuchillo completa. 10x 


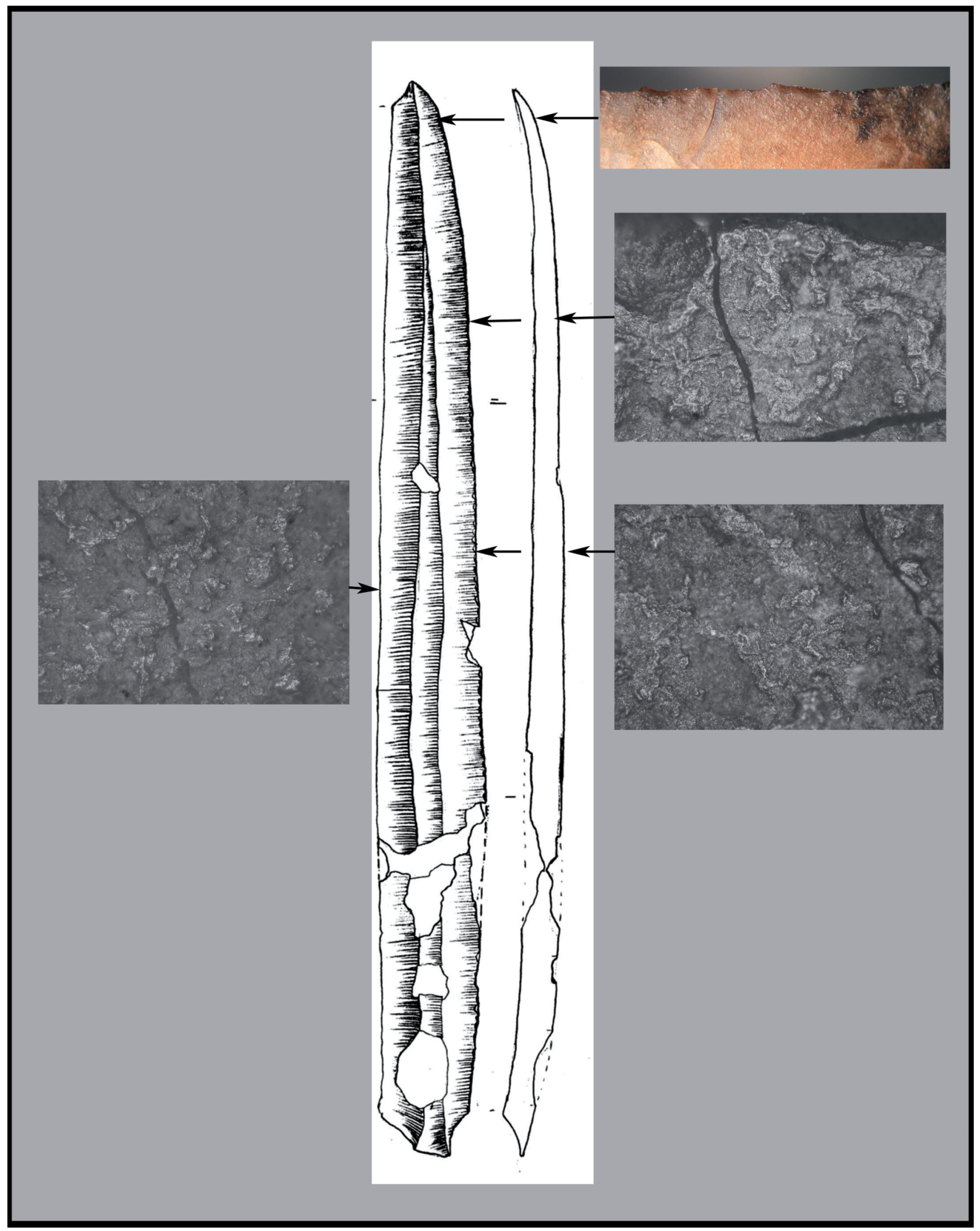

- Figura 5. Lámina-cuchillo. Dibujo A. Gómez Laguna. Fotos: pulimento y desconchados con fisuras térmicas. 


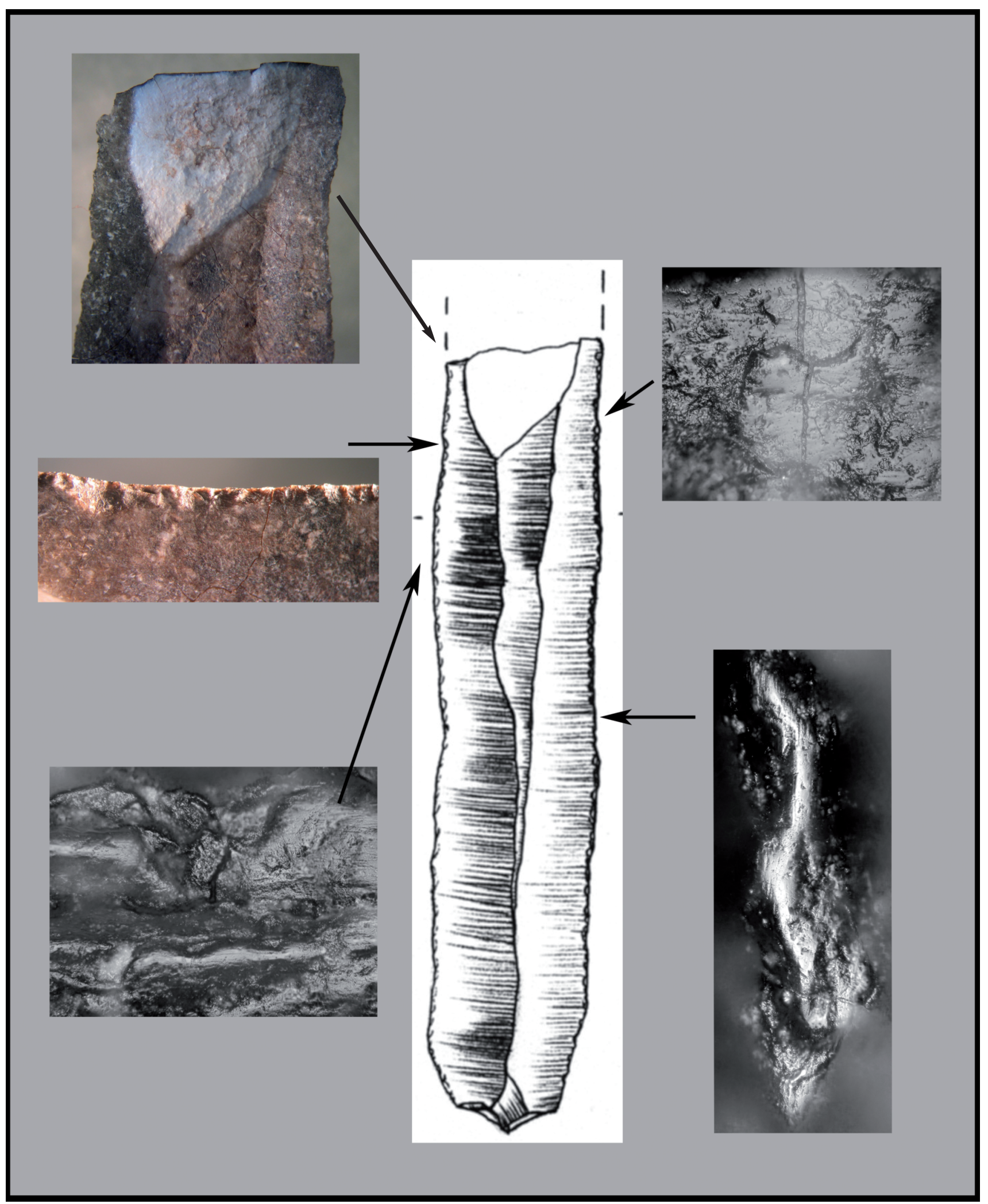

A Figura 6. Fragmento meso-proximal de hoja. Dibujo A. Gómez Laguna. Fotos: macroescama térmica, desconchados y pulimento vegetal. 
Perteneciente también a este mismo individuo tenemos un fragmento meso-proximal de lámina con una gran escama térmica en su cara dorsal. El análisis de huellas de uso ha revelado un trabajo de cortar o segar vegetales en ambos bordes, si bien poco desarrollado en el lateral derecho y apenas iniciado en el izquierdo; en las dos áreas la zona con más intensidad de huellas es el filo activo. Parece tratarse de una lámina fragmentada para ser insertada en una hoz de forma consecutiva por ambos laterales. Su uso, a tenor del escaso desarrollo de pulimento y desconchados, ha sido escaso.

La tercera pieza, el fragmento mesial hallado en un pequeño lote alejado de los cadáveres, muestra la misma funcionalidad que la pieza anterior: cortar o segar vegetales frescos. Destaca en este caso una diferente disposición de cada borde ante el uso. En el lateral derecho las huellas son poco intensas y se desarrollan principalmente a lo largo de la zona intermedia del borde. El lateral izquierdo, por el contrario, se ha empleado con más intensidad y preferentemente en el tercio superior donde se observan, a simple vista, pequeñas áreas del Ilamado lustre de cereal, muy tenues. En ambos bordes huellas como pulimento y estrías ocupan, sobre todo, la cara ventral, mientras que los desconchados tienden a situarse sobre la dorsal. Esto indica una acción de corte con el filo del instrumento ligeramente inclinado. Como sucedía con la lámina anterior, esta pieza parece haber sido usada alternativamente por cada borde, si bien empleando, con preferencia, distinta zona en cada uno.

En el extremo distal de la lámina, se ha configurado una truncadura cóncava mediante retoque semiabrupto. En esta zona se detecta pulimento de cereal asociado al trabajo de una materia muy abrasiva, quizá tierra o piel, que ha producido un fuerte redondeamiento del filo sobre los extremos más salientes de la truncadura; quizá se trata más de un contacto accidental - ¿relacionado con el enmangue?-que un uso intencional dado que los escasos rasgos lineales presentan una distribución caótica. Esta es, sin duda, la lámina más usada, sin embargo, como sucede con las anteriores, el trabajo ejecutado con ella no parece haber agotado definitivamente su uso.

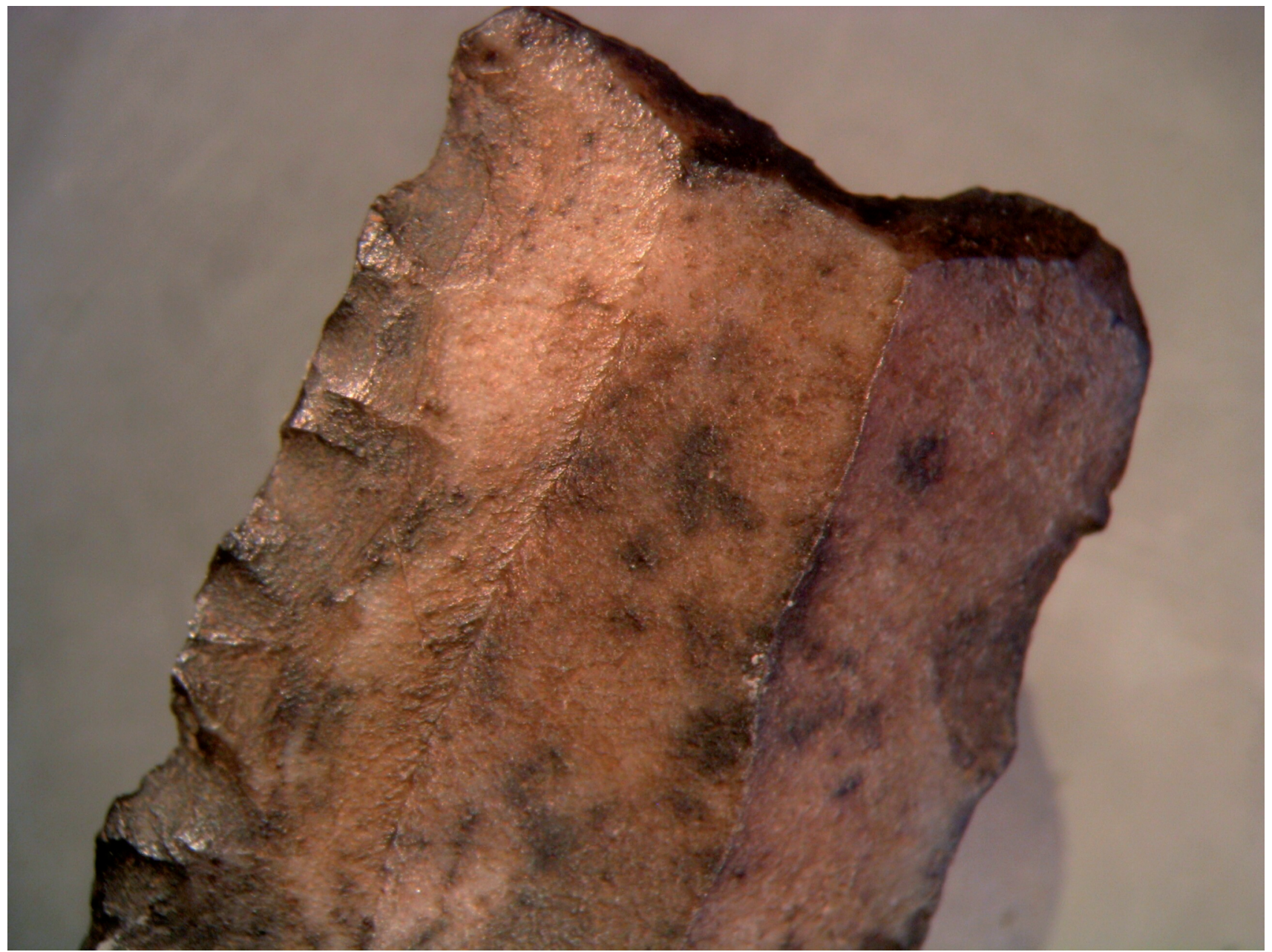

A Figura 7. Extremo proximal del fragmneto mesial de hoja acabado en truncadura cóncava. 4x 


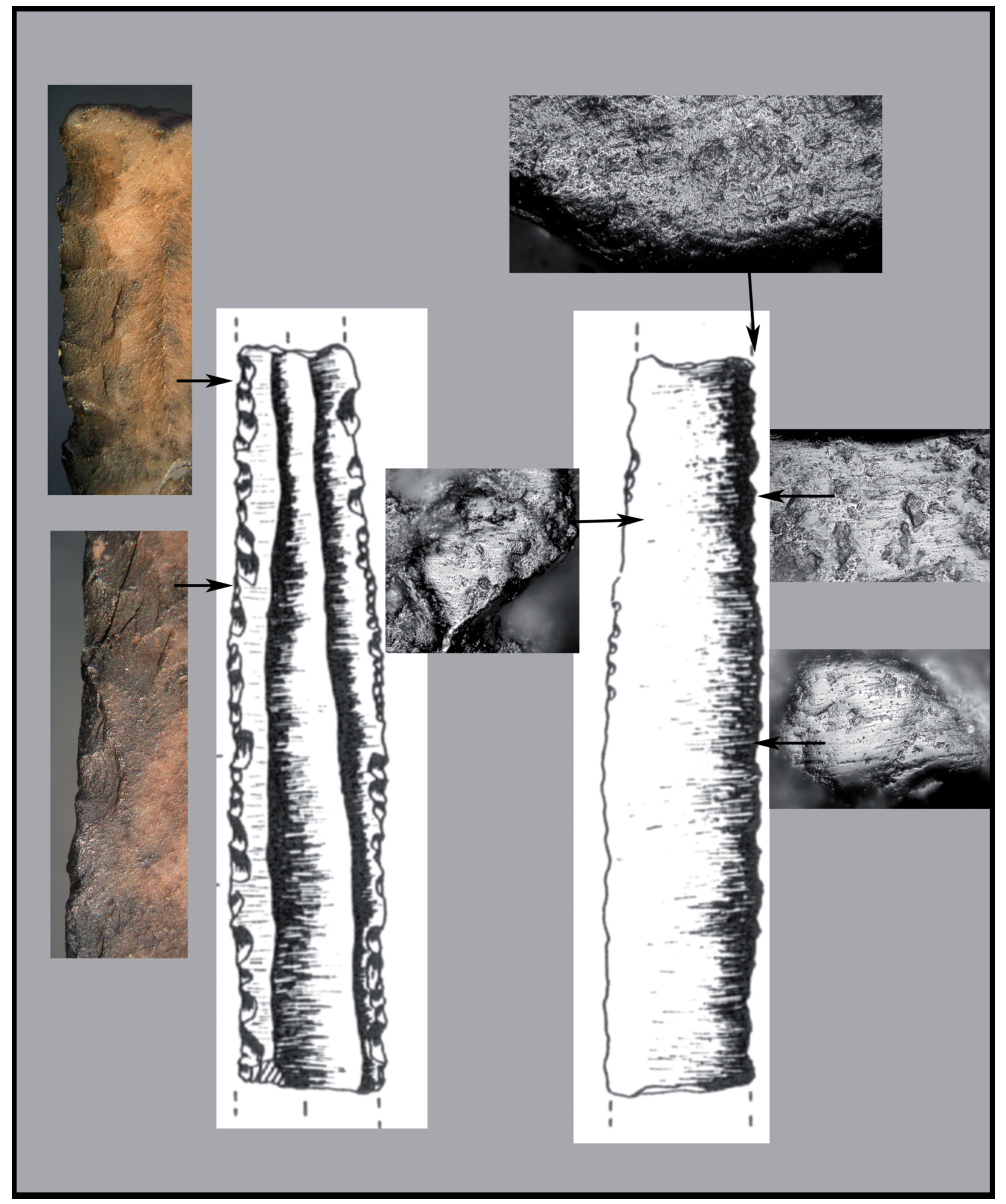

- Figura 8. Fragmento mesial de lámina. Dibujo A. Gómez Laguna. Fotos: desconchados, pulimento y estrías. 


\section{LAS PUNTAS}

El conjunto de puntas de flecha documentadas en el Abrigo I de Cueva Maturras, pone de manifiesto una variabilidad de tipos morfológicos en los 18 ejemplares. En su mayoría poseen pedúnculo y alerones poco evolucionados y contamos con un único ejemplar de morfología romboidal asimétrica (Lomba Maurandi, 1995). Los alerones tienden a ser rectos $y_{\text {, }}$ en menor medida, agudos y obtusos (Hugot, 1957).

Tabla II. Datos tipológicos de las puntas de flecha (Lomba Maurandi, 1995 Revisado)

\begin{tabular}{|l|l|}
\hline Clasificación tipológica & \multicolumn{1}{|c|}{ Puntas } \\
\hline $\begin{array}{l}\text { Punta de flecha de alerones poco } \\
\text { evolucionados }\end{array}$ & $\begin{array}{l}1,2,3,4,9,10,13, \\
15,16,17,18\end{array}$ \\
\hline Punta de flecha de aletas incipientes & 5,12 \\
\hline $\begin{array}{l}\text { Punta de flecha de apéndice redondeado y } \\
\text { aleta incipiente }\end{array}$ & 6 \\
\hline Punta de flecha de alerones evolucionados & 7,8 \\
\hline $\begin{array}{l}\text { Punta de flecha de apéndice redondeado y } \\
\text { alerón poco evolucionado }\end{array}$ & 11 \\
\hline $\begin{array}{l}\text { Punta de flecha foliácea romboidal asimé- } \\
\text { trica }\end{array}$ & 14 \\
\hline
\end{tabular}

La caracterización morfológica de las puntas de flecha examinadas pone de manifiesto la carencia de aletas evolucionadas, sólo en el caso de la punta $n^{\circ} 8$ observamos un desarrollo mayor. A nivel tecnológico, esta carencia puede explicarse dentro de una tradición tecnológica en la que son seleccionados soportes laminares que favorecen el incremento en la longitud de la punta de flecha, condicionando la posibilidad de crear unas aletas evolucionadas.

Los soportes son laminares en la mayoría de los casos, excepto en dos que son sobre lasca. El perfil de las piezas es recto, si bien, en cuatro de ellas, muestra una curvatura hacia el extremo distal. Los filos de las puntas son rectos con una ligera tendencia hacia la convexidad en la parte distal. De las 18 puntas, 11 están completas y en una de ellas se observa una sustitución de la aleta lateral por un filo cóncavo en el extremo proximal que enlaza con el pedúnculo, como consecuencia de una adaptación técnica del tallador al soporte. El resto del conjunto, siete piezas, ofrece distintos tipos de fracturas: seis de ellas han sido causadas por fuego y afectan a dos bases, eliminando parte del pedúnculo o incluso su totalidad, la tercera punta sufre pérdida de perfil lateral incluida la aleta y en la cuarta, la ausencia de extremo distal pudiera achacarse, posiblemente, a afectos térmicos. Dos piezas más presentan una rotura en su zona lateral que elimina una de las aletas y finalmente hay otra pieza con pedúnculo fracturado.

Tabla III. Datos tipométricos retenidos en las puntas de flecha

\begin{tabular}{|c|c|c|c|c|c|c|}
\hline No Inv. & Longitud (mm) & Anchura (mm) & Espesor (mm) & $\begin{array}{c}\text { Índice de } \\
\text { laminaridad }\end{array}$ & $\begin{array}{c}\text { Índice de aplana- } \\
\text { miento }\end{array}$ & Peso (gr) \\
\hline 1 & 42 & 13,5 & 4 & - & - & 2,63 \\
\hline 2 & 55 & 18 & 4,8 & - & - & 3,14 \\
\hline 3 & 43 & 15,9 & 5,9 & 2,70 & 7,2 & 2,55 \\
\hline 4 & 42 & 21 & 6 & 2 & 7 & 3,07 \\
\hline 5 & 33 & 20,1 & 6,1 & 1,64 & 5,4 & 2,36 \\
\hline 6 & 30 & 17 & 5 & 1,76 & 6 & 1,48 \\
\hline 7 & 40 & 18 & 5 & 2,22 & 8 & 2,07 \\
\hline 8 & 49,8 & 22,2 & 5,5 & - & - & 3,63 \\
\hline 9 & 46,1 & 19,9 & 6 & 2,31 & 7,6 & 3,30 \\
\hline 10 & 38 & 15,2 & 4,8 & - & - & 1,91 \\
\hline 11 & 37 & 17 & 6 & 2,7 & 6,1 & 2,44 \\
\hline 12 & 32 & 16 & 4 & 2 & 8 & 1,67 \\
\hline 13 & 48 & 16,2 & 6 & 2,96 & 8 & 3,14 \\
\hline 14 & 40 & 18,2 & 3,5 & 2,19 & 11,4 & 1,75 \\
\hline 15 & 30 & 13,5 & 4 & 2,22 & 7,5 & 1,28 \\
\hline 16 & 56,2 & 21 & 5 & 2,67 & 11,2 & 3,94 \\
\hline 17 & 49 & 19 & 5 & 2,57 & 9,8 & 2,32 \\
\hline 18 & 59 & 15 & 6 & - & - & 3,60 \\
\hline
\end{tabular}


Los parámetros estudiados han sido las medidas de longitud, anchura y espesor máximos. La longitud media de las puntas de flecha es de 40,48 $\mathrm{mm}$ oscilando los valores máximos entre 56,2 y $30 \mathrm{~mm}$ Por su parte, la anchura media es de $17,6 \mathrm{~mm}$ y las medidas extremas son 13,5 y $22,2 \mathrm{~mm}$. El indice de laminaridad tiene su valor medio en 2,26, alcanzando un valor máximo de 2,96 y un mínimo de 1,64. Respecto al segundo parámetro, el espesor medio es de 5'19 mm fluctuando sus medidas máximas entre 3,5 a 6,1 mm. El índice de aplanamiento medio es de 7,93 $\mathrm{mm}$, con valores máximos de $11,4 \mathrm{~mm}$ y mínimos de $6 \mathrm{~mm}$. El espesor máximo se localiza en la parte próximo-mesial.
Las puntas del abrigo I de Cueva Maturras son muy ligeras ya que no alcanzan, en ningún caso, los $4 \mathrm{~g}$ de peso, no obstante hay que tener en cuenta posibles pérdidas de peso debido a la acción del fuego. Las cifras extremas de este parámetro se sitúan entre 3,94 y 1,28 g, quedando establecido el peso medio en 2,57 g. En general tienden a formar un grupo tipológico bastante homogéneo con pedúnculos redondeados y aletas apenas desarrolladas pero de tamaño desigual, sobre todo en la relación longitudanchura. Destacan los ejemplares 16, 17 y 18 por su esbeltez frente a puntas como los números 5,6 y 11, cortas $y$ anchas.

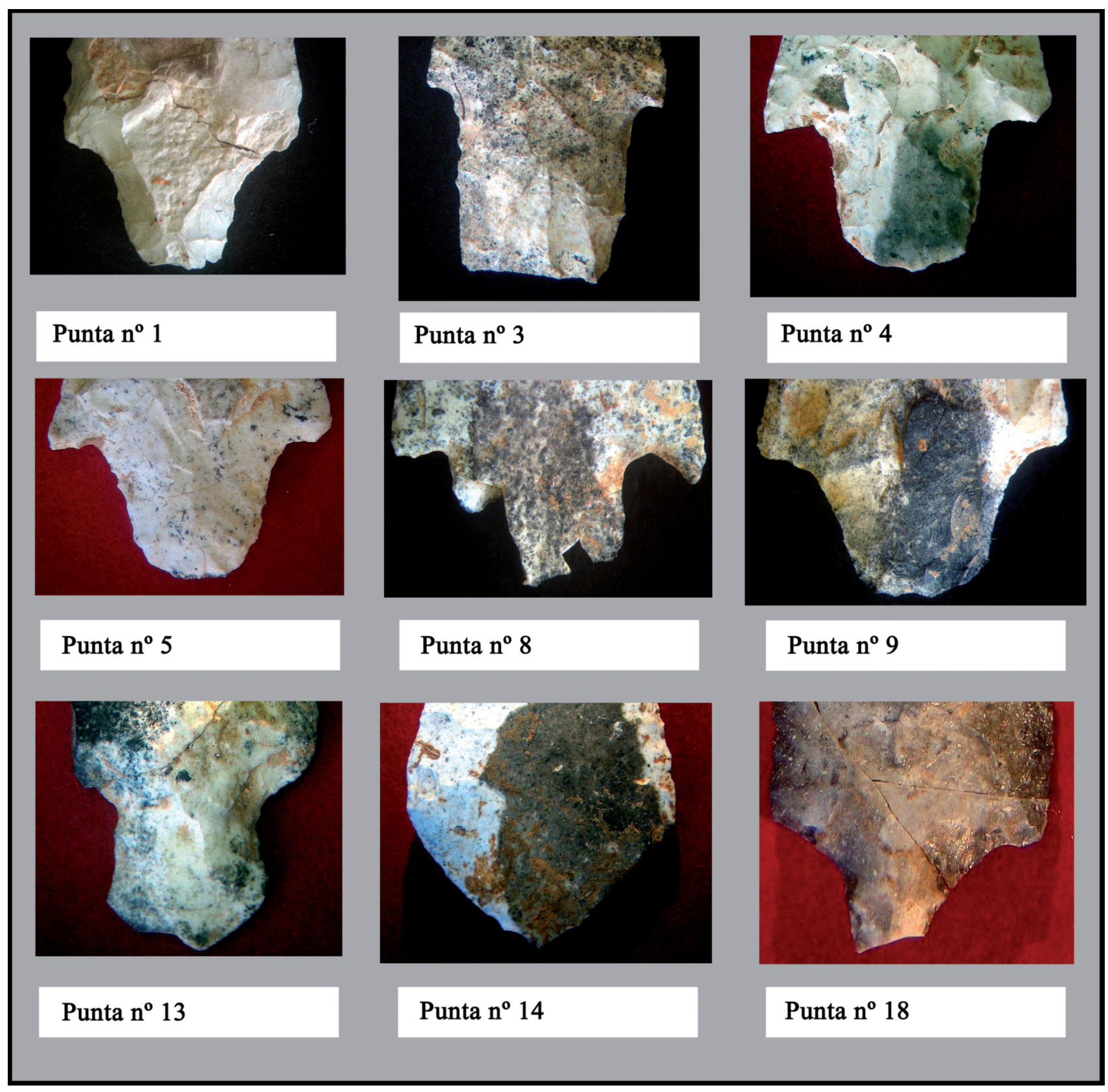

A Figura 9. Detalle de los principales tipos de pedúnculos y aletas. 
El conjunto se caracteriza por puntas con aletas poco evolucionadas, condicionadas por la relación existente entre la morfológía del soporte seleccionado, su longitud, la anchura y espesor. Nueve piezas presentan algún tipo de fractura en una de las aletas por causas diversas. Los perfiles de las mismas son generalmente convexos o rectos con una ligera curvatura hacia el ápice.

Los pedúnculos más comunes son ligeramente rectangulares, a veces de lados convexos, aunque existen cuatro casos de tendencia triangular. Las bases que se conservan, en su mayoría, son convexas apareciendo también dos rectas y una cóncava. En uno de los casos, el pedúnculo muestra sus lados cóncavos simétricos y la base convexa, lo que deduce su método de enmangue. Desde el punto de vista técnico, estas bases han sido rebajadas mediante retoques paralelos y ligeramente oblicuos al eje de simetría de la pieza, en los casos de las rectas y convexas, mientras que en las puntas con pedúnculo triangular la dirección mantenida para las extracciones ha sido oblicua.

Los retoques predominantes son planos, profundos y bifaciales, que en algunas circunstancias pasan a ser sobreelevados sobre distintas zonas como el extremo distal del pedúnculo, las aletas o el ápice distal de la pieza. La excepción la encontramos en el ejemplar $n^{\circ} 15$ en el cual el reverso de la punta ha sido objeto de un retoque marginal cuyo objetivo es la creación de un plano de presión para la extracción de hojitas laminares en el anverso de la punta y en un soporte con una marcada concavidad en su extremo mesial.

Técnicamente, el espesor del soporte no ha condicionado el empleo de un retoque bifacial e invasor presente en la globalidad del conjunto, con negativos de levantamientos que muestran una preparación del plano de presión con las características hojitas con bordes en forma de "U". Se aprecian en los negativos de las extracciones los levantamientos procedentes de lascas inversas (Inizan et al., 1995: 199) en el reverso del soporte 0 , en menor medida, lascas de adelgazamiento bifacial (Whittaker, 1994: 185), probablemente producidas por un percutor blando como el asta de ciervo o semiblando como la arenisca. Por otra parte, hay que tener en cuenta que debido al reducido tamaño de los soportes, la mayoría pueden obedecer a lasquitas de retoque por presión (Fernández López de Pablo, 2004: 62) para la configuración de la morfología final de las puntas. El ángulo de los retoques por presión orientado con respecto al eje de simetría de las piezas suele aumentar de $90^{\circ}$ a $120^{\circ}$ conforme se desarrolla la convexidad de los filos en el extremo distal de la punta.

Las trazas de impacto, es decir, las alteraciones que se producen en la pieza tras su lanzamiento, nos deben permitir determinar si un proyectil ha sido ya lanzado. Tanto el golpe, como la fijación de la pieza en el astil generan fracturas, desconchados y en menor medida estrías, pulimento y embotamientos. Hay que tener en cuenta, sin embargo, que aunque la pieza haya sido lanzada y fracturada, éstos tipos de armas eran muy frecuentemente reavivados, por lo que podemos esperar un cierto sesgo dentro de los conjuntos de piezas fracturadas (Keeley, 1982). Las roturas se producen generalmente cuando el proyectil impacta contra el hueso, y mucho menos frecuentemente si sólo atraviesan carne (Bergman y Newcomer, 1983). Aunque existen varias nomenclaturas para los distintos tipos de fracturas (Dockall, 1997; Fischer et al., 1984), nosotros utilizaremos la más extendida (Bergman y Newcomer, op. cit.). Las más comunes para el ápice son las denominadas como "tipo buril", en lengüeta y en flauta. Existen variaciones sobre éstas principales ("en pluma", "en bisagra", escalonada, etc.), haciendo todas referencia a la terminación de la fractura. Otras fracturas de impacto por uso documentadas durante la experimentación son las de morfología abrupta 0 , en menor medida, transversales o burinantes que afectan a las aletas (Palomo y Gibaja, 2003).

Por otra parte, en ocasiones se observan también entalladuras que se producen en la zona mesial de la pieza a causa de la presión ejercida por el enmangue, no debiendo olvidar, por último, las fracturas producidas por accidentes de talla. La forma en la que la pieza se encuentra unida al fuste influye en que ocurran también fracturas en la zona proximal. Así, si la pieza se encuentra fijada al fuste muy fuertemente, por ejemplo con resina más ligadura, es más fácil que ésta se parta a la altura del pedúnculo, mientras que si la fijación no es tan fuerte es posible que la pieza salte completa del fuste. Además algunos autores asocian los embotamientos y redondeamiento de las aristas a la presencia de un mango (p. ej., Shea, 1991). Si la pieza no se encuentra bien sujeta, el mango fricciona y provoca el redondeamiento. En programas experimentales es posible controlar las marcas debidas a la talla. Las huellas tecnológicas se producen durante el proceso de talla y retoque de la pieza. En ese momento percutores y presionadores son capaces de dejar marcas que en ocasiones pueden confundirse con las de impacto. Entre ellas destacan las huellas causadas por la abrasión y el shearing, o una mezcla de ambos, en los filos tratando de preparar plataformas para el retoque (Gutiérrez, 1998). Las roturas derivadas de los procesos de talla suelen ser rectas y son ciertamente habituales por lo que podemos esperar encontrarlas en piezas procedentes del registro arqueológico.

Por otra parte, hay que decir que también son marcas de impacto características los trazos lineares de pulimento que, al igual que las estrias producidas tras el choque, suelen disponerse paralelos al eje longitudinal de la pieza. Aparentemente se producen cuando los pequeños fragmentos de piedra que se desprenden tras el impacto, entran en contacto con la superficie de la pieza (Moss, 1983). En el caso de las marcas tecnológicas, dichas estrías, muy similares a las de impacto, se dispondrían de forma perpendicular a los filos. 


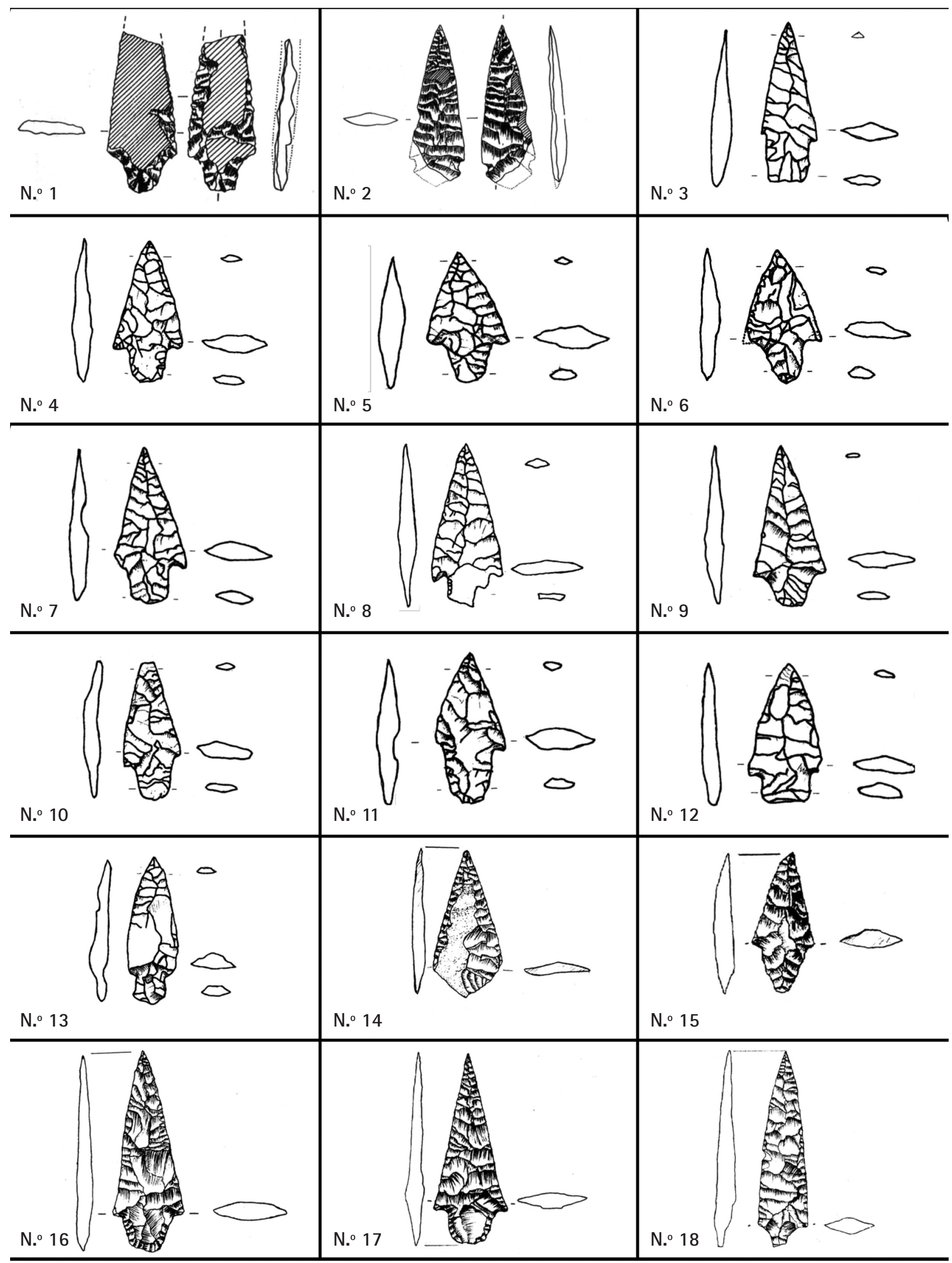

- Figura 10. Puntas de flecha. Dibujos A. Gómez Laguna 
En el caso de las puntas del abrigo I de Cueva Maturras el estudio de huellas se ha revelado muy irregular. La práctica mayoría de las puntas aparecen muy alteradas por la acción del fuego. Bajo el microscopio son comunes espesas capas de pátina que dificultan y llegan a impedir la observación. En conjunto, los tipos de huellas que se han podido percibir se refieren a varias causas.

1. Por fuego. Entre las más comunes fisuras (fig. 12-3) que llegan a formas redes e incluso formas poligonales cuyo estadio más avanzado presenta grietas profundas de bordes muy redondeados (fig. 12-4, 5 y 6). Asociado a estas formas se desarrolla el denominado lustre térmico (Clemente, 1997), es un pulimento espeso y con brillo vitreo de textura muy curvada, sin embargo aparecen otros pulimentos más planos y de textura áspera que pudieran ser formas alteradas del anterior (fig. 12- 6 y 5). Sobre estos pulimentos se detectan, a veces, pequeñas estrías de surco profundo que pueden llevar direcciones caóticas. Pátinas, lustres térmicos en distintos grados y fisuras con 0 sin formas poligonales se han documentado ampliamente en todas las piezas. Otras evidencias son roturas térmicas, claramente en la base de las puntas 2 y 18 y escamas debidas a este fenómeno aparecen en las puntas 7, 11, 12, 13 y 16, llevándose en el caso de la 11 una de las aletas.

2. De talla. En este caso sobre los filos o junto a ellos en los bordes se detectan estrías de percusión aisladas, bien en cinta o aditivas, que suelen llevar direcciones perpendiculares u oblicuas. Son comunes sobre el pedúnculo, la punta y, muy especialmente, en las aletas, zonas que requieren un especial cuidado durante el proceso de retoque. Se han detectado este tipo de estrías sobre 7 de las piezas estudiadas (números 1, 10, 11, 13, 15, 17 y 18). Igualmente se desarrollan pulimento y/o embotamiento asociados o no a estrías que pueden ser debidas a efectos de la preparación de los filos para el retoque (abrasión o shearing), las hemos encontrado en las zonas señaladas sobre 9 piezas $(1,2,3,4,5,6,7,15$, y 16), (fig. 12-2). Las acanaladuras citadas por otros autores (Ibáñez Estévez et alii, 1987) se documentan sobre los bordes de 3 piezas $(1,5$ y 13$)$ e indican una zona de contacto con el percutor/presionador (fig.12-1). Algunas de las fracturas distales, de morfología plana, pueden deberse también a accidentes de talla; este tipo de fractura aparece en las puntas 1, 3 y 10, si bien la primera está tan extremadamente afectada por el fuego que no podemos excluir que se trate de una fractura térmica. No obstante, aunque a simple vista el resto de los ápices parecen enteros, bajo la lupa binocular se detectan, en prácticamente toda la muestra, mínimas roturas que pueden ser debidas al proceso de talla o, también, a causas accidentales.

3. Por uso. Las principales huellas derivadas estrictamente del uso son las causadas por el impacto. Son principalmente estrías de impacto -siempre paralelas al eje de la pieza- y las roturas descritas de ápice y aletas. Hemos podido documentar una pequeña rotura en buril sobre el ápice de la punta $n^{\circ} 14$, pero el desarrollo del supuesto golpe de buril es muy corto por lo que mantenemos dudas sobre su utilización. Se detectan estigmas proximales en la punta $n^{\circ} 8$, con roturas de tipo irregular que no parecen de tipo térmico. Aletas de fractura abrupta aparecen en 4 piezas $(4,5,7$ y 12 , si bien, esta última con fisuras próximas de fuego). Respecto a las estrías de impacto paralelas o ligeramente oblicuas al eje hemos localizado este tipo de huellas en 4 piezas ( 1,3 , 4 y 12), en todos los casos poco marcadas debido a la presencia de pátinas, por lo que no podemos descartar, tampoco, que estas huellas sean fruto de algún choque accidental ajeno al uso; por ello preferimos considerarlas como huellas que indican una posible utilización, sin excluir otras causas de formación (fig. 12-7 y 8).

4. Huellas relacionadas con el uso. Son aquellas incidencias, sufridas por la pieza, relacionadas con la funcionalidad pero no directamente con el impacto. Entre ellas las diferencias de coloración, quizá atribuidas a la presencia de un mango que pudo proteger la parte proximal de la pieza. Se aprecian de forma neta en la punta 4 y más difusamente en los números $3,8,10$ y 17 . Finalmente se observan sobre el borde lateral izquierdo del pedúnculo en la cara dorsal de la punta 3 restos de una estructura tabular (fig. 12-9) con color pardo que pudiera corresponder a alguna fibra (¿vegetal?) quizá utilizada para encajar la base de la punta en el mango.

5. Huellas accidentales. Este apartado recoge aquellas improntas dejadas sobre el útil tanto en vida (golpes, pisoteo...) como durante la sedimentación y posteriores trabajos arqueológicos. Es probable que algunas de las roturas mencionadas o incluso alguna estría de impacto, así como parte de las zonas con pulimento débil, embotamiento y estrías caóticas pudiera haber sido causada por choques o roce con el sedimento, si bien, en esta cavidad la mayor parte de los restos mostraban pocas evidencias de rodamiento. El trabajo arqueológico ha dejado sus improntas en forma de estrías sobre varias puntas, en este caso asociadas bien a grafito bien a brillo de metal. 


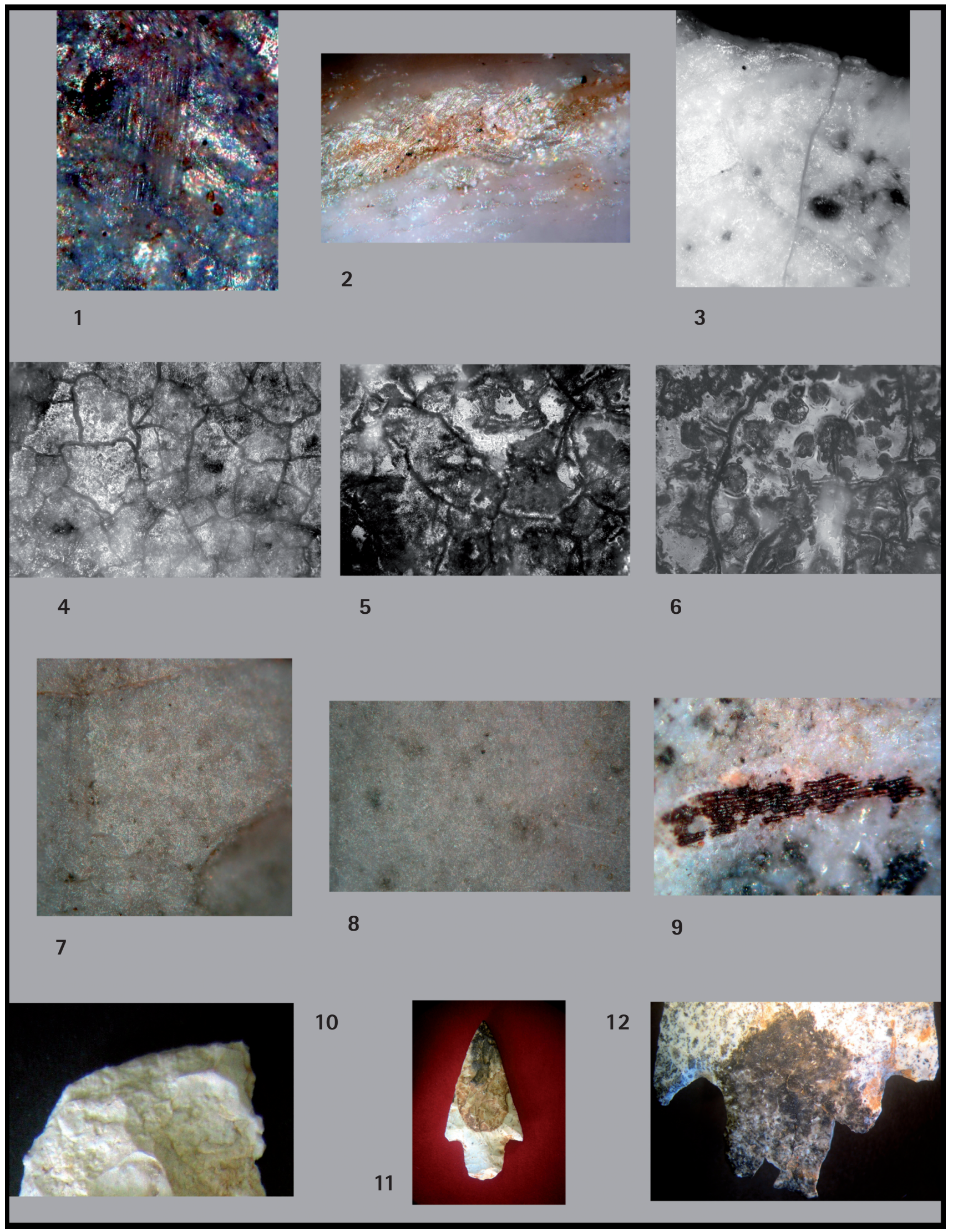

- Figura 11. Huellas microscópicas de fuego, talla y uso. 


\section{APORTACIÓN DE LOS ANÁLISIS}

FUNCIONALES A LA DETERMINACIÓN DE

LA NATURALEZA DE “DEPÓSITOS” DE PUNTAS DE FLECHA EN CONJUNTOS FUNERARIOS

La presencia durante el Holoceno de flechas en contextos rituales nos hace preguntarnos por la intencionalidad del depósito. En ocasiones las piezas vienen incluidas en los cadáveres y son, por tanto, y en muchas ocasiones evidencia de la causa de su muerte. En otras, las puntas de flecha constituyen ofrendas rituales al difunto y son muy abundantes en contextos funerarios a partir del mesolítico. El análisis de las flechas desde una óptica funcional nos permitirá determinar cuándo una punta ha sido utilizada y cuándo no.

Guilaine y Zammit (2002), en su revisión sobre las evidencias de violencia observadas a partir de restos arqueológicos prehistóricos, consideran que ésta es inherente al ser humano, incluso durante el paleolítico. Es, sin embargo, en momentos postpaleolíticos cuando asistimos a una generalización de las evidencias arqueológicas de conflictos. No nos extenderemos con la descripción de los numerosos restos existentes que tienen que ver tanto con la presencia de restos humanos con puntas de flecha clavadas, como con flechas en su entorno (que pueden ser evidencias de impactos en los tejidos blandos). Uno de los casos más conocidos es el del individuo congelado encontrado en 1991 en el glaciar de Similaun (Italia), el cual no sólo conserva una punta de flecha de pedúnculo y aletas clavada en el hombro, sino que muestra diversas fracturas ya curadas en las costillas que también pueden ser signo de violencia (Zur Nedden et al., 1994; Gostner y Vigl, 2002).

Las puntas de flecha, dada su cuidada factura y su importancia dentro de la economía del grupo son, en ocasiones, elementos de prestigio. ¿Se depositaron con intención de ofrenda? o ¿esas puntas fueron las que mataron a los alli enterrados? Ahí es donde los estudios traceológicos pueden aportar la respuesta. Es posible que se prefieran puntas no usadas para depositar como ofrenda aunque no se puede descartar que también se colocaran junto al difunto puntas ya usadas. Los estudios de trazas de impacto, junto con los antropológicos y de distribución espacial de las puntas en relación con los cadáveres, deben ser así complementarios (Márquez, 2004). En la península lbérica se están llevando a cabo estudios de esta indole sobre conjuntos procedentes de contextos funerarios generalmente protohistóricos. Como señalan Palomo y Gibaja (2002), existen importantes diferencias en cuanto al grado de fracturación de los depósitos de puntas de los contextos del neolítico medio catalán y los del neolítico final-calcolítico, mostrando los primeros un bajo grado de fracturación y los segundos un mayor porcentaje de piezas utilizadas. Entre estos últimos queremos destacar los yacimientos de Longar en Navarra (Armendáriz e Irriga- ría, 1995) y San Juan Ante Portam Latinam en Álava (Vegas, 1999). En ambos casos se observa que las puntas han venido incluidas en los cuerpos. A veces se encuentran directamente clavadas en el hueso y otras veces, al encontrarse muy relacionadas con los cadáveres, como hemos señalado más arriba, pudieron venir clavadas en las partes blandas. En la necrópolis neolítica de la Bóvila Madurell se recuperaron dos esqueletos que no presentaban ningún ajuar asociado. Uno de ellos llevaba clavada una punta de flecha en una vértebra torácica. La postura anómala, así como la ausencia de ajuar, lleva a pensar a los responsables del estudio que quizás los dos individuos fueron enterrados sin ninguna consideración por el mismo grupo que los mató (Campillo et al., 1993). En contraposición a los anteriores, en la cueva megalítica calcolítica de Can Martorell (Barcelona) se podría observar, a juicio de los investigadores, y dada la presencia de piezas de factura muy cuidada y no fracturadas, la existencia de depósitos rituales (Palomo y Gibaja, op. cit.).

En cuanto a la función simbólica de las flechas, es posible que nunca obtengamos respuesta a ciertos comportamientos que observamos en grupos actuales, como por ejemplo la existencia de determinados tabúes en torno a las flechas. Los Danis de Indonesia distinguen entre flechas de guerra y flechas para caza (Petrequin y Petrequin, 1990). Además existen también diferencias en los tipos y número de flechas del carcaj según la edad del individuo, siendo el "kit" más variado el que llevaría un adulto. Se trata de sistemas muy complejos que podemos esperar que en parte existieran durante la prehistoria. Desgraciadamente son aspectos invisibles para el arqueólogo y no podemos esperar más que intuirlos gracias a las comparaciones etnográficas.

Si volvemos nuestra mirada al abrigo 1 de cueva Maturras resulta difícil decidir que circunstancias rodean a las puntas del ajuar funerario. Los estigmas del fuego hacen que algunas de las huellas asociadas al impacto no puedan dilucidarse con claridad. Por otra parte la ubicación de las puntas es, en si, peculiar. Las puntas de flecha número 1, 2, y 3 se hallaban alejadas no sólo de los cuerpos sino de cualquier otro resto de ajuar, siendo las $n^{\circ} 1$ y 3 algunas de las que más posibles huellas de uso y/o enmangue ofrecen. El resto de las puntas aparecían al lado del individuo no 1 , pero mientras las piezas número 4 a 13 se situaban junto a sus manos, los ejemplares 14 a 18 estaban próximos o sobre la parte inferior del cuerpo, en ambos lotes hay evidencias de uso, si bien no todas tan claras como sería deseable.

\section{CONCLUSIONES}

El ajuar lítico tallado se ha visto sometido a una fuerte acción por fuego que se manifiesta en el desarrollo de cúpulas térmicas con desprendimiento de masa y fracturas, así como otros estigmas variados, hecho que ha dificultado enormemente el análisis traceológico. 
La presencia de talones diedros y características morfológicas de las hojas apuntan a su obtención mediante una talla por presión procedente de la explotación unipolar del frente amplio de un núcleo. Podemos catalogar el ejemplar completo de gran hoja-cuchillo de sílex y considerar su estatus de objeto de prestigio (Ihuel, 2004: 58). Su uso, si bien con ciertas dudas, ha podido ser el de trabajos asociados a carnicería, como desollar y descarnar. Las dos hojas restantes muestran su empleo preferente como elementos de hoz sobre materias vegetales blandas, quizá cereales, alternando su uso en los dos bordes. El gran cuchillo y uno de los elementos de hoz aparecian junto al individuo $\mathrm{n}^{\circ} 1$, pero tanto estas piezas de ajuar individual, como la del ajuar colectivo -el otro elemento de hoz- permanecian aún en uso ya que no están totalmente agotadas.

El análisis comparativo de los parámetros tipométricos y tecnomorfológicos retenidos en las puntas de flecha muestran una homogeneidad en relación a morfotipos documentados y longitudes máximas conservadas, en los que predominan el retoque plano, invasor y bifacial, presentando una mayor variabilidad en la elaboración de los pedúnculos pero, en prácticamente todos los casos, muestran una cuidada manufactura. Los estigmas de impacto son poco claros y aparecen sobre poco más de la tercera parte de la colección (8 piezas sobre 18).
De todas las puntas, 15 se asocian al individuo $n^{\circ} 1$, quien parece poseer todo el conjunto lítico tallado a excepción de cuatro piezas. No hay ningún caso claro de punta clavada sobre el esqueleto, el lote junto a las manos de este individuo puede hacer alusión a un puñado de flechas completas depositadas junto a él o bien a una reserva de puntas guardadas, quizá, en algún tipo de saco. En todo caso, con la salvedad de 4 puntas rotas en sus extremos distales o proximales (alguna fractura por fuego) la mayor parte de las puntas se depositaron en estado de ser usadas.

Los ajuares líticos tallados del Abrigo 1 de Cueva Maturras muestran, junto al resto de los materiales, un conjunto de instrumentos y armas de carácter funcional, que pudieron formar parte de los enseres de los difuntos en vida y fueron depositados probablemente para acompañarlos en su viaje al más allá (Gutiérrez Sáez, Gómez Laguna, Ocaña Carretón, 2002). El depósito de estas piezas talladas en el enterramiento tuvo que representar un esfuerzo económico por parte de la comunidad ya que se trata de herramientas y armas de talla muy cuidada cuya materia prima no abunda en el entorno. Sin embargo, no todas las piezas parecen haberse hecho "ex profeso" para este propósito ya que las láminas y algunas puntas evidencian, de una manera no muy intensa, un uso anterior.

\section{BIBLIOGRAFÍA}

ARMENDÁRIZ, A. E IRIGARAY, S. (1995): Violencia y muerte en la prehistoria. El hipogeo de Longar. Revista de Arqueología, 168: 16-29.

Bergman, C. A. y Newcomer, M. H. (1983): Flint arrowhead breakage: examples from Ksar Akil, Lebanon. Journal of Field Archaeology, 10: 239-243.

BINDER, D. (1984): Systèmes de débitage laminaire par pression : exemples chasséens provençaux. Tixier, J. ; Inizan, M.-L. y Roche, H. (eds.) Préhistoire de la pierre taillée, 2: économie du débitage laminaire. Paris. Cercle de Recherches et d'Etudes Préhistoriques: 71-84.

CAMPILlO, D.: MerCADAl, O. y BLANCH, R-M. 1993: A mortal wound caused by a flint arrowhead in individual MF-18 of the Neolithic Period exhumed at Sant Quirze del Valles. International Journal of Osteoarchaeology, 3: 145-150.

Clemente CONTE, I. (1997): Thermal Alterations of flint implements and the conservation of microwear polish: preliminary experimental observations, Siliceous rocks and culture: 525-535. Universidad de Granada, Monográfica Arte y Arqueología.

DoCKALL, J. E. (1997): Wear traces and projectile impact: a review of the experimental and archaeological evidence. Journal of Field Archaeology, 24: 321-331.

FERnÁNDEZ LÓPEZ DE PABLO, J. (2004): Las puntas foliáceas en el horizonte campaniforme: Hacia una definición de los contextos de producción. M.S. Hernández Pérez (Ed): La Edad del Bronce en tierras valencianas y limitrofes: 59-63.

Fischer, A.; Vemming Hansen, P. y Rasmussen, P. (1984): Macro and Micro wear traces on lithic projectile points. Experimental results and prehistoric examples. Journal of Danish Archaeology, 3: 19-46.

FORENBAHER, S. (1999): Production and exchange of bifacial flaked stone artefacts during Portuguese Chalcolithic. BAR International Séries, 756. Oxford.
Gallet, M. (2002): Pour une technologie des débitages laminaires préhistoriques. CNRS, Paris.

GOSTNER, P. Y VIGL, E. E. (2002): Report of radiological-forensic findings on the Iceman. Journal of Archaeological Science, 29: 323-326.

GUILAINE, J. Y ZAMMIT, J. (2002): El camino de la guerra. La violencia en la prehistoria. Ariel. Barcelona.

GutiérRez SÁEz, C. (1998): Las huellas de talla. Baena Preysler, J. (coord.): Tecnología lítica experimental. Introducción a la talla de utillaje prehistórico. BAR International Series, 271: 205-210. Oxford.

GutiérReZ, C.; GómEZ, J. A. y OCAÑA, A. (2000): El enterramiento múltiple del abrigo de Cueva Maturras (Argamasilla de Alba, Ciudad Real). Benitez de Lugo Enrich, L. (coord): El Patrimonio Arqueológico de Ciudad Real. Métodos de trabajo y actuaciones recientes: 43-66.

Gutiérrez Sáez, C.; Gómez laguna, A. y Ocaña Carretón, A. (2002): Fuego y ritual en el enterramiento colectivo de Cueva Maturras (Argamasilla de Alba, Ciudad Real). Rojo Guerra, M.; Kunst, M. (eds) Sobre el significado del fuego en los rituales funerarios del Neolítico. Studia Archaeologica 91: 99-126. Universidad de Valladolid. Caja Rural de Soria. Instituto Arqueológico Alemán.

Hugot, H. S. (1957): Essai sur les armatures de pointes de flèches de Sahara, Lybical Anthropological : 89-236. Alger.

Ibañez EstéVez, J. J.; González UrquiJo, J. E.; Lagüera García, M. A. y GutiéRREZ SÁEZ, C. (1987): Huellas microscópicas de talla. Kobie, 16 : 151-161.

IHUEL, E. (2004): La diffusion du silex du Grand Pressigny dans le Massif Armoricain au Néolithique. Documents Préhistoriques 18.

INIZAN, M. L. ; BALLINGER M. R.; ROCHE H. Y TIXIER J. (1995): Technologie de la Pierre taillée. Tome 4. C.N.R.S. Nanterre.

KEELEY, L. H. (1982): Hafting and retooling: effects on the Archaeological record. American Antiquity, 47: 798-809. 
LOMBA MAURANDI, J. (1995): Las industrias líticas talladas del Eneolítico/Calcolitico en la Región de Murcia. Tipología, distribución y análisis contextual. Edición en microfichas. Universidad de Murcia.

MÁrouez Mora, B. (2004): Los análisis traceológicos como forma de reconstruir las actividades prehistóricas: el caso de la caza. Baquedano, E., y Rubio, S., (eds.), Miscelánea en homenaje a Emiliano Aguirre. Arqueología. Zona Arqueológica. Vol. IV: 300-311.

Moss, E. (1983): The functional analysis of flint implements. Pincevent and Pont d'Ambon: two cases from the french final Palaeolithic. B.A.R. International Series, 177. Oxford.

Nedeen, D. ZuR.; Wicke, K.; KNAPp, R.; SeIDLER, H.; Wilfing, H.; Weber, G.; SpindleR, K.; Murphy, W. A.; Hauser, G. y Platzer, W. (1994): New findings on the Tyrolean "Ice Man": archaeological and CT-Body analysis suggest personal disaster before dead. Journal of Archaeological Science, 21: 809-818.

Ocaña Carretón, A.; Gómez laguna, A. J.; Gutiérrez Sáez, C. y Sanguino GonzÁlEZ, J. (1999): Resultados preliminares del sondeo realizado en el sitio de Cueva Maturras (Argamasilla de Alba, Ciudad Real). Actas del XXIV Congreso Nacional de Arqueología: 143-154. Cartagena.

PALOMO I Pérez, A. Y GibAjA BAO J. F. (2003): Anàlisi tecnomorfológica/funcional $i$ experimental de les puntes de fletxa. La Costa de Can Martorell (Dosrius, El Maresme). Mort i violencia en una comunitat del litoral català durant el tercer mil-lenni aC. Laietania 14: 179-214. Museu de Mataró.

Palomo, A. y GibajA, J. F. (2002): Análisis de las puntas del sepulcro calcolitico de la Costa de Can Martorell (Dosrius, Barcelona). I. Clemente, R. Risch y J. F. Gibaja (eds.): Análisis Funcional. Su aplicación al estudio de Sociedades Prehistóricas. Bar International Series, 1073. Oxford.
Pelegrin J. (1984a): Systèmes expérimentaux d'immobilisation du nucleus par pression. Tixier, J.; Inizan, M.-L. y Roche, H. (eds.) Préhistoire de la pierre taillée, 2: économie du débitage laminaire. Paris. Cercle de Recherches et d'Etudes Préhistoriques: 105-116.

Pelegrin, J. (1984b): Approche technologique expérimentale de la mise en forme de nucleus pour le débitage systématique par pression. Tixier, J.; Inizan, M.-L. y Roche, H. (eds.) Préhistoire de la pierre taillée, 2: économie du débitage laminaire. Paris. Cercle de Recherches et d'Etudes Préhistoriques: 93-103.

PeLEGRIN, J. (1988): Débitage expérimental par pression "Du plus petit au plus grand". Technologie Préhistorique: 37-52. CNRS, Paris.

Petrequin, A. M. y Petrequin, P. (1990): Flèches de chasse, flèches de guerre. Le cas des Danis d'Irian Jaya (Indonésie). Bulletin de la Société Préhistorique Farnçaise 87: 484-511.

SHEA, J. J. (1991): The behavioral significance of levantine Mousterian industrial variability. Ph. D. dissertation, Harvard University, Cambridge, M.A. Ann Arbor. University Microfilms.

Terradas, X. Palomo, A., GibajA, J. F. y Clop, X. (2005): Primeros resultados sobre el estudio de grandes láminas procedentes de contextos funerarios del Nordeste de la Península lbérica. P. Arias Cabal, R. Ontañón Peredo y C. García -Moncó Piñeiro (eds.): III Congreso del Neolitico de la Península lbérica Santander.

TEXIER, P. J. (1984): Le débitage par pression et la mécanique de la rupture fragile. Tixier, J.; Inizan, M.-L. y Roche, H. (eds.) Préhistoire de la pierre taillée, 2: économie du débitage laminaire. Paris. Cercle de Recherches et d'Etudes Préhistoriques: 139-147.

Vegas Aramburu, J. I. (1999): San Juan Ante Portam Latinam. Exposiciones del Museo de Arqueologia de Álava. Diputación Foral de Álava.

WHITAKER, J. C. (1994): Flintknapping. Making and understanding stone tools. University of Texas Press. Austin. 